\title{
¿Ciudad creativa y ciudad sostenible?: Un análisis crítico del "modelo Barcelona" de políticas culturales
}

Creative Culture and the Sustainable City? An Analysis of the Barcelona Cultural Policy Model

Cité créative et cité durable? Une analyse critique du modèle Barcelone de politiques culturelles

Ma. Victoria Sánchez Belando, Joaquim Rius Ulldemolins y Matías I.

Zarlenga

\section{OpenEdition}

\section{Journals}

Edición electrónica

URL: http://journals.openedition.org/rccs/5101

DOI: $10.4000 /$ rccs.5101

ISSN: 2182-7435

Editor

Centro de Estudos Sociais da Universidade de Coimbra

Edición impresa

Fecha de publicación: 1 diciembre 2012

Paginación: 31-50

ISSN: 0254-1106

Referencia electrónica

Ma. Victoria Sánchez Belando, Joaquim Rius Ulldemolins y Matías I. Zarlenga, « ¿Ciudad creativa y ciudad sostenible?: Un análisis crítico del "modelo Barcelona" de políticas culturales », Revista Crítica de Ciências Sociais [En línea], 99 | 2012, Puesto en línea el 04 septiembre 2013, consultado el 30 abril 2019. URL : http://journals.openedition.org/rccs/5101 ; DOI : 10.4000/rccs.5101 


\section{MA. VICTORIA SÁNCHEZ BELANDO JOAQUIM RIUS ULLDEMOLINS MATÍAS I. ZARLENGA}

\section{¿Ciudad creativa y ciudad sostenible?: Un análisis crítico del "modelo Barcelona" de políticas culturales}

La cultura se ha convertido en uno de los elementos decisivos en el desarrollo económico, social y de la identidad de las ciudades. En este sentido, las políticas culturales han efectuado un giro local y emprendedor, lo que se ha descrito como la ciudad creativa. No obstante, de forma creciente han aparecido voces que propugnan nuevos paradigmas en el que la cultura contribuya a un desarrollo más sostenible. En este contexto, Barcelona ha desarrollado un modelo de política cultural que se ha presentado como una síntesis equilibrada del modelo de ciudad creativa y ciudad sostenible. En este sentido, el gobierno local ha liderando el movimiento de ciudades a favor de una política cultural sostenible y participativa. No obstante, algunas medidas de la política cultural en la planificación de los equipamientos culturales, la participación cultural o la generación de grandes eventos nos indican que la estrategia implementada se enfrenta con grandes contradicciones y limitaciones en cuanto a la participación de la comunidad artística y la comunidad local.

Palabras clave: Barcelona (España); ciudad creativa; ciudades; política cultural; sustentabilidad urbana.

Palavras-chave: Barcelona (Espanha); cidade criativa; cidades; política cultural; sustentabilidade urbana.

\section{Introducción}

Barcelona se ha convertido en un modelo de desarrollo local con éxitos reconocidos a nivel internacional. Este modelo se basa en una estrategia emprendedora donde la cultura tiene un rol fundamental en las estrategias de regeneración urbana y desarrollo económico. Los pilares de este modelo se basan en los grandes eventos, la gobernanza y participación del sector cultural, el desarrollo de instituciones culturales de excelencia y el liderazgo 
de redes de ciudades, que han convertido a Barcelona en un modelo de referencia por su capacidad de innovar en el discurso sobre la política cultural. Una de estas innovaciones ha sido el impulso de la Agenda 21 de la Cultura ${ }^{1}$ que sitúa a la sostenibilidad y la participación como nuevas tendencias de política cultural. Una orientación que se presenta como compatible con la orientación emprendedora, basada en el modelo de ciudad creativa. El apogeo del discurso fue el Fórum Universal de las Culturas de 2004. La hipótesis de este artículo es que desde entonces se ha vislumbrado una oposición que ya existía desde los años noventa. Esta oposición se basa en una disyuntiva entre el modelo de ciudad creativa y de ciudad sostenible; y que la causa de esta tensión la debemos buscar en el modelo de gestión emprendedor como límite a la participación social efectiva en las políticas culturales.

El presente artículo explora la emergencia del paradigma de la ciudad creativa y de la sostenibilidad en la cultura, teniendo en cuenta el giro local y emprendedor en el que se inscriben. A continuación caracterizaremos el surgimiento y desarrollo del "modelo Barcelona" de política cultural para indagar en diversos aspectos clave de la política cultural del Ayuntamiento de Barcelona, evaluando si en estas actuaciones podemos encontrar un equilibrio entre la orientación de la ciudad creativa y la ciudad sostenible tal y como plantea el discurso oficial del gobierno de la ciudad o si bien se trata de orientaciones que se contradicen. La presente investigación se centra en: la planificación de los grandes equipamientos culturales, los centros culturales de proximidad, los instrumentos de gobernanza y participación, y el desarrollo del Fórum de las Culturas de 2004.

A nivel metodológico, nos basamos en el análisis de fuentes documentales como las memorias, los presupuestos y los documentos elaborados por la propia administración, así como en el análisis de contenidos de las entrevistas generadas en el marco de la investigación sobre el sistema de la política cultural en Catalunya. ${ }^{2}$

\section{Creatividad, sostenibilidad y giro local de la política cultural a) La emergencia del discurso sobre creatividad}

El impacto de las transformaciones de las políticas públicas y culturales en las ciudades contemporáneas resulta incomprensible si no se remite a su contexto de elaboración y aplicación inicial: los centros urbanos del Reino Unido durante la década del ochenta y noventa del siglo xx. El fin del modelo

\footnotetext{
${ }^{1}$ Ver: http://www.agenda21culture.net/index.php?lang=es.

${ }^{2}$ Esta investigación ha sido elaborada en el Centro de Estudios sobre Cultura, Política y Sociedad, dirigida por el profesor Arturo Rodríguez Morató (2011) y financiada por el Ministerio de Ciencia e Innovación (Ref. CSO2008-05910/SOCI).
} 
de producción fordista, basado en la industria pesada y la línea de montaje, supuso para muchas ciudades del Reino Unido -surgidas al calor del industrialismo-el cierre de numerosas industrias y sus consecuencias: un alto índice de desempleo, la emigración y el deterioro urbano (Lash y Urry, 1998).

En correlación con estas transformaciones económicas se instrumenta una política de desregulación y descentralización estatal fomentada por el gobierno neoconservador thatcherista. De esta manera, a mediados de la década de los ochenta, las políticas de descentralización y desregulación estatal -en un sentido vertical (crecimiento de las competencias locales y regionales en detrimento de las nacionales) y horizontal (inclusión de otros actores no gubernamentales en la toma de decisiones)- conducen a la elaboración de estrategias de desarrollo a partir de la competencia entre ciudades (Brenner, 2004; Jessop, 2004).

Pero no es sino hasta comienzos de la década de los noventa cuando surge un movimiento que incluye a planificadores urbanos, agencias no gubernamentales y dependencias administrativas, que entienden a la cultura como un elemento central para la regeneración urbana, el desarrollo económico y la inclusión social (García, 2004b). Este tipo de estrategia supone una ruptura con las antiguas formas en las que algunas administraciones conciben y utilizan lo cultural, sea para la creación de una identidad nacional a la distancia a través de elementos de la llamada alta cultura, la orientación de democratización cultural, o para integrar diferentes expresiones culturales, según el paradigma de la democracia cultural (Urfalino, 1996). La cultura se entiende e instrumentaliza ahora en un sentido muy diferente, como un bien o servicio que puede reportar un beneficio económico directo para las ciudades, sea a través de estrategias vinculadas a la construcción de imagen de las ciudades para el atractivo turístico (branding) o como industria o sector para el desarrollo económico (industrias creativas).

El uso estratégico de la cultura genera la confluencia de geógrafos, urbanistas, economistas y responsables por las políticas públicas para la elaboración de un nuevo tipo de planificación urbana que incluye a la cultura como elemento central. Así, se pasa de la planificación urbana a la planificación cultural en las ciudades (Evans, 2001). A través de diversos planes, estrategias de competitividad entre ciudades (como es el caso de las Capitales Culturales Europeas) o megaeventos culturales (como el Fórum de las Culturas 2004 en Barcelona) se despliegan una serie de acciones que tienen por finalidad el desarrollo económico y la regeneración de los centros urbanos a partir de las industrias creativas y el turismo (García, 2004a).

Los discursos y las prácticas que se fundamentan dentro del paradigma de la sostenibilidad cultural emergen como una respuesta crítica al discurso 
y las políticas de la creatividad aplicadas en el ámbito urbano. Las principales críticas sobre este tipo de discursos y políticas tienen por eje: (1) Los procesos de segregación, desplazamiento y aburguesamiento espacial generados a nivel urbano [ciudad creativa]; (2) El entendimiento y uso de la cultura como un tipo de activo para el incremento de valor simbólico o material [economía creativa]; (3) La exclusión de los actores sociales locales (movimientos sociales, asociaciones vecinales, grupos de artistas, etc.) en la toma de decisiones y en el blanco de las propuestas [clase creativa]. Estas tres críticas se relacionan directamente con las consecuencias de la instrumentalización de políticas vinculadas al fomento de las ciudades creativas, el desarrollo de la economía creativa y las políticas sobre la atracción de la llamada clase creativa. Para el discurso de la sostenibilidad cultural estos tres factores convierten en insostenible el discurso sobre la creatividad. En su lugar proponen un nuevo paradigma que tenga en cuenta factores como la equidad social, el respeto medioambiental, la economía responsable y la vitalidad cultural. Los actores que generan este tipo de discursos provienen del ámbito de la consultoría y del académico y, aunque no de manera sistemática, de los movimientos socio-culturales.

\section{b) Sostenibilidad y participación cultural}

La conceptualización y operativización de los discursos sobre creatividad como elemento generador de valor -económico o social-, en el contexto de los nuevos modelos de desarrollo urbano, toma dos orientaciones diferenciadas para responder a una misma problemática de partida: (1) la de los retos económicos, sociales, culturales y medioambientales planteados con la crisis del modelo de acumulación industrial y (2) la tendencia de las ciudades a reconfigurar su modelo de acumulación en base a la denominada economía cultural (Scott, 1999).

Cada uno de estos modelos se interpreta como formas de instrumentalización divergentes de la creatividad y del rol de los creativos en la ciudad. Sin embargo, el concepto de cultura y creatividad que subyace a cada uno es bien diferente. Así, el enfoque de la sostenibilidad, aparece como respuesta crítica a esta orientación de planificación pública presentada como modelo de éxito y fuertemente influida por las recomendaciones de Richard Florida (2002).

El enfoque de la sostenibilidad ha adquirido notable relevancia en el mundo anglosajón, tanto en el ámbito de la planificación pública, como en el académico (Jeannotte y Duxbury, 2010). El estudio de la relación cultura-sostenibilidad emerge ligado a la planificación pública; así, el análisis de las tensiones entre nivel conceptual-normativo-operativo de la sostenibilidad 
ocupa un lugar central en la literatura sobre el tema, donde confluyen discursos académicos, de consultoría y la propia perspectiva de la comunidad artística y local sobre la sostenibilidad como problemática. Este carácter se expresa en la delimitación del concepto de cultura que propone Jon Hawkes "Empiezo proponiendo una descripción de la cultura que es útil en el contexto de la planificación pública" (Hawkes, 2001:3) y en el aporte de autores como Duxbury y Jeannotte (2010) y Kagan y Hahn (2011) que, dese una mirada holística, focalizan en la correlación entre conceptos-operativización y la acción en la dinámica social y cultural urbana.

Uno de los argumentos centrales de la sostenibilidad es el cambio de la base de legitimación de la cultura. Si bien en el modelo de la ciudad creativa el acento está puesto en su legitimación económica, en el modelo de la sostenibilidad la cultura se legitima por su capacidad para vehiculizar valores que faciliten transformaciones sociales hacia un modo de vida sostenible como elemento central para el bienestar social, económico y medioambiental. Dentro de estas transformaciones la creatividad, como rasgo común a los seres vivos (Kagan y Hahn, 2011), resulta clave. Desde esta mirada la cultura, se plantea como una forma de agencia (Sewell, 1992) y tiene un carácter preeminentemente participativo, donde los creativos son catalizadores del cambio social y del empoderamiento comunitario; "agentes de transpolinización intercultural entre diferentes redes y contextos urbanos”. (Kagan y Hahn, 2011: 19).

Asimismo, el enfoque de la sostenibilidad no invalida completamente los principios del paradigma de la creatividad en sí, sino que cuestiona su expresión economicista que tiende a afectar negativamente la sostenibilidad ambiental, económica y la equidad social como bases para la resiliencia de una comunidad (Duxbury y Jeannotte, 2011; Hawkes, 2001). Por otra parte, el enfoque de la sostenibilidad se propone hacer un re-enmarque de algunos aspectos de la ciudad creativa en la lógica de la ciudad sostenible, a partir de la re-conceptualización del concepto de creatividad y de sus usos sociales (Kagan y Hahn, 2011).

\section{c) El giro local y emprendedor de la política cultural}

Estas nuevas orientaciones comportan a su vez un giro local y emprendedor de la política cultural del que Barcelona representa un caso destacado (Rodríguez Morató, 2005). Este giro se inscribe en un proceso iniciado en los años ochenta y desarrollado en los noventa de toma de consciencia de la interrelación entre diferentes sectores de la cultura (público-privado-tercer sector) impulsando una mirada sistémica e integral más allá de las políticas tradicionales de fomento sectorial (Cherbo y Wyszomirski, 2000). En consecuencia, la política cultural local ha evolucionado de la perspectiva de la 
planificación y provisión directa de servicios culturales al rol de facilitador y catalizador (Duxbury y Jeannotte, 2010), instalando con esta acción, escenarios potencialmente más participativos, dado el nuevo planteamiento en la relación entre sector privado, tercer sector y la ciudadanía en general en la creación, en la gestión cultural y en el diseño de políticas dirigidas al sector cultural. No obstante, esta potencialidad no se ha concretado de forma equilibrada y en cambio parece, como veremos, haberse materializado un predominio creciente de los sectores privados en la política cultural.

Un indicador de esta tendencia ha sido el desarrollo de mecanismos locales de participación cultural, imitando los consejos de las artes de ámbito nacional o regional, en el que se consensua en grados diversos los objetivos y los instrumentos de la política cultura local. No obstante, esta mayor preeminencia de lo local en la política cultural, tiene su contrapartida en la creciente desarticulación de las políticas culturales nacionales redistributivas y en la creciente competencia entre las ciudades y los gobiernos locales para atraer inversiones y captar mayores recursos públicos (Menger, 2010).

En general, debemos situar este giro local de la política cultural dentro de lo que se ha calificado como "estrategia emprendedora de los gobiernos locales" (Harvey, 1989) y que sustituye a la planificación centralizada y orientada principalmente a la redistribución (Menger, 2010). Los gobiernos locales, frente a los retos del cambio económico proponen estrategias para potenciar el desarrollo económico, cuya manifestación en cultura han sido los museos-bandera (Gómez y González, 2001) y los grandes eventos culturales de proyección internacional (García, 2004a). Una estrategia desarrollada especialmente en grandes ciudades como Birmingham, Liverpool o Barcelona que han querido, a partir de la cultura, ejercer de capitales regionales con ambiciones de proyectarse a nivel internacional (Barber y Pareja Eastaway, 2010). Esta estrategia emprendedora de los gobiernos locales tiene a la vez el objetivo de implicar al sector privado y a las administraciones superiores (regional y nacional) para desarrollar proyectos que el gobierno local por sí sólo no podría abordar por su dimensión económica, estableciendo de este modo modelos de gobernanza complejos que se escapan de la planificación pública tradicional. En definitiva, la orientación emprendedora en política cultural parte de una voluntad de desarrollo local pero plantea diversos retos, el primero: la capacidad de establecer un equilibrio entre necesidades locales y proyección externa.

\section{El caso de Barcelona}

a) La cultura y el desarrollo de la ciudad: génesis del "modelo Barcelona"

Tal y como analiza Arturo Rodríguez Morató (2005; 2008) la estrategia cultural de Barcelona cuenta con un largo e intenso desarrollo hasta llegar 
a nuestros días. Durante la segunda mitad del siglo XIX y durante el primer tercio del siglo xx, Barcelona experimentó un vertiginoso desarrollo industrial, que la lleva a convertirse en una gran ciudad moderna. Pero esta transformación se desarrolla al margen del ineficaz y centralista Estado español. Será la acción concertada de las elites locales y del poder local quien lidere este proceso: a partir de la creación de servicios básicos e instituciones de prestigio, y también de la promoción de grandes eventos, como las Exposiciones Universales de 1888 y 1929, hitos decisivos en la internacionalización de la ciudad. Esta singular tradición de activismo mancomunado de las elites y el poder local se eclipsa, obligadamente, durante el franquismo, pero resurge al recuperarse el margen de maniobra democrática y se convierte entonces en un activo fundamental de la ciudad ante los nuevos y urgentes retos que la crisis del modelo fordista plantea. Es así como en los años ochenta Barcelona desarrollará uno de los modelos más avanzados de ciudad emprendedora (Marshall, 1996).

El llamado "modelo Barcelona" se inició en los años ochenta como un impulso modernizador de la ciudad bajo los sucesivos gobiernos socialdemócratas, ${ }^{3}$ caracterizándose por la aplicación de un urbanismo socialmente inclusivo y culturalmente avanzado (Marshall, 2000). Asimismo, el modelo se definía por: (1) la generación de grandes eventos culturales como elemento de transformación material y simbólica de la ciudad (Subirós, 1998), (2) una apuesta por la colaboración público privado en la generación de proyectos urbanos de interés público y (3) el protagonismo de los técnicos (arquitectos, urbanistas, gestores culturales) en el desarrollo del proyecto urbano (Muntaner, 2007).

De forma creciente, el "modelo Barcelona" ha ido recibiendo diversas críticas. Una de ellas es que la transformación urbana ha favorecido los intereses de las nuevas clases medias en detrimento de las clases populares (Julier, 1996) y que paulatinamente se ha orientado a la promoción económica externa y no a la satisfacción de las necesidades ciudadanas (Degen y García, 2012). Pero en general hay un consenso en que el "modelo Barcelona” es un modelo de éxito en el que se combinó de forma acertada renovación urbana y planificación cultural (Subirós, 1999). Por otra parte, Barcelona es una ciudad con un considerable patrimonio y actividad cultural, que este modelo de desarrollo urbano consiguió preservar y potenciar. Las elites locales, conscientes de esta situación, han convertido a la cultura en

\footnotetext{
3 Las primeras elecciones municipales democráticas de 1979 dieron la victoria al Partido de los Socialistas de Cataluña que desde entonces ha gobernado la ciudad de forma ininterrumpida hasta 2011, en la que ha ganado Convergencia i Unió, una coalición de la derecha nacionalista.
} 
un elemento central en la redefinición de estrategias de futuro para la ciudad (Rodriguez Morató, 2008). Y el gobierno local de la ciudad ha apostado por convertir los sectores culturales y del conocimiento, además del turismo, en vectores para el desarrollo de la economía local (Trullén, 2001).

\section{b) El desarrollo del "modelo Barcelona" de política cultural}

La ciudad de Barcelona llega a finales de los años setenta, después del largo periodo dictatorial, con grandes déficits en política cultural (Font, 1991). En esta etapa, el gobierno local desarrollará casi en solitario la tarea de recuperar el importante patrimonio cultural heredado, puesto que la Administración Central del Estado se centrará rápidamente en los equipamientos culturales de Madrid a los que dedica la mayor parte de los recursos, mientras que el gobierno autonómico, dedicará sus esfuerzos a dotarse de una administración cultural propia al margen de la realidad cultural existente en los municipios de la provincia de Barcelona.

No obstante, a partir de mediados de los años ochenta, desde la nominación de Barcelona a los Juegos Olímpicos de 1992, el gobierno local pasa a liderar los proyectos de modernización urbana y a la vez los de construcción de equipamientos culturales siempre aplazados por falta de fondos (como el Museo de Arte Contemporáneo), implicando en la tarea a las administraciones autonómica y estatal. En consecuencia, el desarrollo de las infraestructuras culturales en la etapa democrática se realiza bajo el signo del voluntarismo municipal y sin una planificación previa. Sin embargo, contará con la complicidad del sector cultural y buena parte de las élites sociales barcelonesas que ayudarán a viabilizar estos proyectos presionando al gobierno central y autonómico para que se impliquen financieramente. Esta dinámica generará un modelo de gobernanza cultural en el que el gobierno municipal tendrá un protagonismo muy superior al que le otorga el marco competencial, generalizando la estructura de consorcio entre administraciones para la gestión de la mayoría de grandes equipamientos y eventos culturales. Podemos decir por lo tanto, que el "modelo Barcelona" de políticas culturales se basará en consecuencia en el mismo modelo emprendedor desarrollado en las políticas urbanísticas y de desarrollo local.

Finalmente, a partir de los años noventa el gobierno municipal adoptará un modelo de administración de la cultura agencializado, creando un organismo autónomo en 1996, el Instituto de Cultura de Barcelona, que gestionará más del 70\% del presupuesto municipal (Ajuntament de Barcelona, 1980-2012) con la intención de facilitar la gobernanza cultural. En resumen, estrategia emprendedora, liderazgo en la gobernanza, participación del 
sector privado, agencialización en la política cultural serán los rasgos identificadores del "modelo Barcelona" de política cultural (Rius, 2005). Todo ello parece situarle en la línea de la ciudad creativa. No obstante, el gobierno municipal ha defendido siempre que su estrategia buscaba un modelo propio, un equilibrio entre la proyección internacional y la dinámica local, el desarrollo de las industrias culturales y el desarrollo de la participación cultural (ICUB, 1995). A continuación analizaremos el "modelo Barcelona", el impulso y límites de este modelo de equilibrios.

\section{c) El "modelo Barcelona": cuun equilibrio entre la instrumentalización y la genera- tividad cultural?}

Barcelona en sus primeros años de gobierno democrático verá suceder diversos modelos de política cultural que pondrán más el acento en la participación cultural y festiva o en la recuperación del patrimonio artístico. No obstante, tras los Juegos Olímpicos y la exitosa campaña de dinamización cultural emprendida durante su preparación (Subirós, 1998) surgirá un nuevo paradigma de política cultural que intentará potenciar el sector cultural en su conjunto y de forma equilibrada como objetivo principal (Rius, 2005).

El gobierno socialdemócrata barcelonés, imitando al Nuevo Laborismo británico, convertirá la cultura en un signo de modernidad y la defenderá como una estrategia post-neoliberal para un desarrollo, competitivo a nivel internacional e inclusivo socialmente (Belfiore, 2004). No obstante, la política cultural no será vista como un simple instrumento para acompañar la política social o de promoción económica. Sino que según sus responsables, ésta debe asumir la responsabilidad del liderazgo en pro de un proyecto de ciudad global "y hacer más presente la cultura en la vida de la ciudad para convertir Barcelona en incubadora de capital intelectual” (ICUB, 1995).

Esta orientación se verá confirmada en el primer plan estratégico del sector cultural, que fijará sus objetivos en aumentar la capacidad de generar valor cultural de Barcelona (ICUB, 1999). El Plan de Acción Municipal (2000-2003) muestra también este intento de equilibrio entre objetivos extrínsecos e intrínsecos del sector cultural. Es decir, se fija como objetivo convertir a la cultura "en una de las piezas clave para posicionar Barcelona como ciudad del conocimiento" o destacar su "valor social que mejora la calidad de vida, la integración y la cohesión social" (Ajuntament de Barcelona, 2000), pero también en enfocarse a lo que Menger ha calificado como generatividad cultural (Menger, 2010). En efecto, la política cultural intenta orientarse prioritariamente a "impulsar la capacidad de generar contenidos culturales" a partir de incrementar las sinergias entre el patrimonio 
cultural, el capital humano de los profesionales y los artistas y las empresas productoras y gestoras de cultura" (Ajuntament de Barcelona, 2000).

Este intento de ofrecer una respuesta equilibrada a los dilemas de la política cultural (Bianchini, 1993) se consolidará a partir de finales de los años dos mil con el desarrollo de la Agenda 21 de la Cultura, que situará a Barcelona en una de las posiciones de vanguardia del desarrollo de una estrategia sostenible y participativa para la política cultural local.

\section{d) El desarrollo de la Agenda 21 de la Cultura: Barcelona en la vanguardia de la orientación sostenible y participativa de la política cultural}

Desde hace más de una década el "modelo Barcelona" quiso orientarse hacia el paradigma de la sostenibilidad entonces emergente, siendo por tanto uno de los actores pioneros en su elaboración y defensa. Este posicionamiento a favor de una política cultural sostenible nace en el marco del encuentro de Eurocities $^{4} 2002$ en Barcelona, donde se defendió la idea de la cultura como uno de los motores del desarrollo de las ciudades y de la sostenibilidad y la inclusión social como principios orientadores de esta perspectiva, que se sigue defendiendo frente a opciones puramente economicistas (Eurocities, 2010). Aprovechando esta experiencia en el liderazgo de las redes internacionales de ciudades, Barcelona impulsa desde entonces la Agenda 21 de la Cultura, cuyos principios orientadores se aprobaron en 2004 en el marco del IV Foro de Autoridades Locales para la Inclusión Social de Porto Alegre reunidas en el Foro de las Culturas de Barcelona e inmediatamente fueron adoptados por la asociación internacional de gobiernos municipales, United Cities and Local Governments (UCLG).

La Agenda 21 de la Cultura, que desde entonces tiene el secretariado permanente en Barcelona y recibe el apoyo del Ayuntamiento de Barcelona, se plantea como un compromiso para orientar las políticas culturales como instrumento de promoción de "los derechos humanos, la diversidad cultural, la sostenibilidad, la democracia participativa y la generación de condiciones para la paz" (Pascual, 2008). Este compromiso se traduce en una serie de recomendaciones, entre las que se encuentra situar la gobernanza, la sostenibilidad y la participación en el corazón de las políticas culturales locales. Una orientación que según la UCLG se concreta en una política cultural dirigida a "la estimulación de la participación democrática de los ciudadanos en la formulación, el ejercicio y la evaluación de las políticas públicas en

\footnotetext{
${ }^{4}$ Eurocities es una organización europea de coordinación de ciudades. Fundada por cinco ciudades en 1986 entre las que se encontraba Barcelona, se ha convertido en uno de los actores institucionales de la Unión Europea y actualmente tiene sede en Bruselas.
} 
cultura" así como "el reforzamiento de la cultura como esfera pública basada en la libertad de expresión, el conocimiento crítico". Una esfera "nutrida por los agentes y los profesionales de la cultura así como de las expresiones culturales de la ciudadanía” (UCLG, 2006).

Visto este esfuerzo de la política cultural barcelonesa por defender a nivel internacional la sostenibilidad y la participación, es legítimo por lo tanto plantearse hasta qué punto ha aplicado a nivel local estas recomendaciones y en el caso de que exista discordancia entre discurso internacional y práctica local, preguntarse el porqué y en qué medida nos sirve para caracterizar el "modelo Barcelona" de política cultural.

\section{El "modelo Barcelona": ¿un modelo sostenible y participativo? Contraste entre discursos y realizaciones}

a) La red de equipamientos culturales de proximidad: los centros cívicos

Uno de los ejes de una política cultural basada en los principios de la sostenibilidad es el impulso de la participación en el ámbito de la cultura. En el caso de la ciudad de Barcelona, el gobierno local asumió, desde 1979 en adelante, la participación como un objetivo prioritario en el marco de una agenda socialdemócrata. Esta orientación del discurso del gobierno local hacia la generación de estructuras más permeables se ha ido plasmando en leyes, normativas, programas, planes estratégicos y en el diseño de variados sistemas y mecanismos de participación institucional que no garantizan por su mera existencia practicas participativas (Font, 2001).

En la planificación y provisión de infraestructuras, la traducción de estos objetivos participativos dirigidos a la ciudadanía y al sector socio-cultural se materializó en la creación en 1982 de los Centros Cívicos, equipamientos socio-culturales de proximidad. La inserción en la agenda política del gobierno local de tendencia socialdemócrata de la necesidad de crear infraestructuras socio-culturales en los barrios, surge de la tensión entre una dinámica top-down y una bottom-up. Aunque la elaboración y definición de la política de equipamientos de proximidad, finalmente, se inscribe en una dinámica burocrática. Desde el punto de vista del modelo de gestión municipal, los Centros Cívicos son parte del giro local de las políticas públicas y la emergencia del municipalismo keynesiano (Brugué y Gomà, 1998).

Así, en el contexto olímpico, se programó toda una serie de nuevos equipamientos culturales que llenaban huecos históricos en el mapa de servicios culturales de la ciudad, aunque su ubicación fue decidida en función del plan general de desarrollo urbano, con vistas a crear nuevas centralidades o para reactivar áreas deprimidas. Este es el contexto político-administrativo en el que nacen los Centros Cívicos, imbuidos por una interpretación de la 
cultura cercana a la noción de "cultura común" (Willis, 1990) y por objetivos de participación social; al mismo tiempo que insertos en un plan general de transformación urbana basado en estrategias que tomaban la cultura como trampolín para el desarrollo de la ciudad.

El programa de monumentalización de la periferia y el plan de Centros Cívicos se plantean como parte de esta política de renovación urbana (Subirós, 1999). Por ello, los Centros Cívicos, se instalan sistemáticamente en edificios viejos de interés histórico-arquitectónico singular y que a la vez se sitúan como puntos de referencia de la zona, como antiguas fábricas o cooperativas y viejos palacios residenciales (ibidem). La rehabilitación de estas instalaciones como Centros Cívicos, respondía no sólo a una demanda social sino también a la necesidad de reapropiarse colectivamente de la historia y los símbolos del lugar, así como a la de salvar un patrimonio cultural de alto interés. Así, tomando la construcción discursiva de la planificación de estos equipamientos, podría argumentarse que estaban guiados por una orientación cercana al enfoque de la sostenibilidad, en la que la cultura es entendida en términos de creatividad terrena, como una práctica inserta en la vida diaria (Willis, 1990) puesto que la participación ocupaba un lugar central, así como la preservación del patrimonio histórico-cultural como elemento de cohesión y reflexión comunitaria.

Sin embargo, por un lado, el rechazo del movimiento de vecinos a causa de la percepción de los equipamientos como el resultado de una política top-down que les exigía adecuarse a una participación regulada por el Ayuntamiento y a renunciar a sus expectativas de autogestionar centros socio-culturales pre-existentes con soporte público, y, por otro, la reconfiguración de la política cultural en los años noventa que se desplazaba -en el marco del giro emprendedor- del énfasis en los objetivos clásicos del paradigma democratizador y de la democracia cultural, a la forma de lo que se ha denominado nuevo paradigma de política cultural (Rius, 2005) provocaron una crisis de articulación de estos equipamientos respecto de las políticas culturales y de su función comunitaria. Además, en este contexto, la gestión fue externalizada a empresas privadas desvinculadas del tejido local. Con esto, los centros cívicos, quedaron al margen, tanto de la dinámica cultural comunitaria como de la planificación cultural, perdiendo, principalmente, su potencial como espacios de participación en la gestión y en la creación cultural comunitaria. En 2010, los Centros son incorporados al Instituto de Cultura de Barcelona bajo un nuevo signo, más orientado al modelo de la ciudad creativa (Sánchez, 2010). 


\section{b) La gobernanza y la participación cultural: de los planes estratégicos al Consejo de la Cultura de Barcelona}

El Ayuntamiento de Barcelona fue pionero en el desarrollo de planes estratégicos de la cultura en España y su desarrollo forma parte del modelo de políticas culturales barcelonés (Guillemat, 2008). Estos planes partían de la idea de fomentar la capacidad de crear valor cultural local a través del fortalecimiento de los vínculos entre todos los actores que intervienen en el ámbito de la cultura (público-privado-tercer sector), y de todas las fases de la cadena de producción cultural (creación-producción-difusión), así como de promover colaboraciones interdisciplinares. A medio camino entre dispositivo de planificación y gobernanza, los planes estratégicos han mostrado la creciente consciencia del sector cultural sobre las interrelaciones entre los diversos sectores y segmentos y su rol central en el desarrollo social y económico de la ciudad.

No obstante, este proceso de reconocimiento y legitimación de la cultura como recurso para el desarrollo social y económico, no tuvo la misma intensidad en relación a su potencial como herramienta y como espacio para la participación de la ciudadanía y de los profesionales del sector cultural. La percepción de falta de permeabilidad y un papel limitado de los mecanismos de participación existentes en el sector cultural, impulsaron a la administración local a generar respuestas que se vienen materializando desde el inicio de la democracia en el diseño de diversos sistemas de participación en la políticas locales y de un marco regulatorio de la participación por parte del Ayuntamiento.

Por este motivo, resultado del último plan estratégico del 2006 se formuló la necesidad de crear un organismo de participación, que se concretó en 2010 en la figura del Consejo de la Cultura de Barcelona como "órgano de participación, de relación, de debate, de coordinación y de seguimiento de la implementación de los objetivos del plan estratégico de cultura" (ICUB, 2006). No obstante, este organismo tiene carácter consultivo y sus informes no son vinculantes para los responsables de la política cultural. Además, su composición se basa en criterios de representación de los sectores culturales. Con este tipo de características, sectores con capacidad de lobby-como el sector del teatro- tienen mucha influencia por su peso económico. Así, queda eclipsada la voluntad de facilitar la participación de la ciudadanía o de los diferentes sectores de la comunidad artística. ${ }^{5}$ Otra vez, la estrategia

\footnotetext{
5 Por ejemplo, en 2012 recomendó no unificar la gestión de los equipamientos culturales de Barcelona y a pesar de ello, el Centro de Cultura Contemporánea de Barcelona y la Filmoteca han quedado bajo la dirección del Museo de Arte Contemporáneo de Barcelona (cf. Consell de la Cultura de Barcelona, 2011).
} 
emprendedora que otorga un papel central al sector privado, impide una participación social más amplia y el desarrollo de una orientación centrada en articular la política cultural a las necesidades de la comunidad local y de sus artistas.

c) El Fórum 2004: las contradicciones entre ciudad creativa y ciudad sostenible Quizá uno de los casos en los que el "modelo Barcelona" de política cultural ha proyectado de forma más cruda sus contradicciones ha sido el Fórum de las Culturas 2004. En su desarrollo como proyecto de reordenación de una zona en proceso de degradación (la desembocadura del río Besós) y como proceso de renovación de infraestructuras sostenibles (la construcción de una depuradora de aguas eficiente y de una instalación de placas solares fotovoltaicas) el Fórum fue sin duda un ejemplo de excelencia. No obstante, su evaluación es mucho menos positiva si nos centramos en su efecto como plan general de regeneración urbana o como evento cultural dirigido a promover la sostenibilidad, la participación y la paz (Majoor, 2011).

El Fórum de las Culturas se planteó inicialmente como una repetición de la estrategia de los Juegos Olímpicos del 1992 en la que se generó un entusiasmo cívico a favor de un proyecto de desarrollo local, que combinaba la transformación urbana con el desarrollo del atractivo cultural de la ciudad (García, 2004a; Rodriguez Morató, 2008). En este caso, la idea de un gran evento relacionado con la sostenibilidad se concretó en la presentación en la UNESCO en 1997 del proyecto, organismo que formalmente mostró su apoyo a la iniciativa, a pesar de su carácter aún indefinido. Posteriormente, el Plan de Acción Municipal de 2000 del Ayuntamiento de Barcelona definía el Fórum como

un acontecimiento de carácter global, innovador en los formatos y los contenidos y con la voluntad de ser la primera edición de un nuevo tipo de cita mundial periódica con el acento puesto en las culturas y las personas, persiguiendo la movilización de amplios sectores de la sociedad civil, con motivo de la construcción de nuevas relaciones sociales en el mundo de la globalización. (Ajuntament de Barcelona, 2000)

El Fórum se planteó como un modelo mixto entre un festival de las artes interdisciplinar, un congreso temático y un foro de movimientos sociales. En este último caso, el Fórum se inspiraba en el Fórum Social de Porto Alegre, reunión bianual del movimiento antiglobalización en el que los movimientos sociales se reúnen para discutir los problemas planteados por la globalización económica y las alternativas a los proyectos de las grandes 
corporaciones, los grandes Estados y los organismos internacionales. No obstante, la incorporación en el organismo gestor del Fórum de representantes del gobierno autonómico catalán y del gobierno central, ambos dominados por partidos conservadores, hizo que esta vertiente participativa quedara en una pura retórica. Asimismo, en el mismo esquema emprendedor favorecido por el Ayuntamiento, se buscó el financiamiento de las grandes empresas, algunas de la cuales son acusadas de prácticas ambientalmente negativas (Endesa) o de participar en el negocio armamentístico (Indra).

Esta exclusión de los movimientos sociales y de los sectores más críticos de la comunidad creativa, junto con la participación de gobiernos a favor de la guerra de Irak (en la que España participó) y de empresas multinacionales objeto de críticas por favorecer prácticas opuestas al discurso oficial del Fórum, generó que éste fuese visto, por parte de los sectores que podían aportar un interés intelectual y un elemento de creatividad como un ejercicio de manipulación y de hipocresía por parte de su promotor, el Ayuntamiento de Barcelona. Una percepción que acabó con una campaña de boicot al Fórum, la Asamblea de Resistencia al Fórum que tuvo un notable impacto mediático y social (Espai en Blanc, 2004). En este contexto, los mismos responsables de la política cultural que habían iniciado el proyecto dimitieron de la dirección del Fórum y se distanciaron, pero quedó en evidencia, otra vez, la incapacidad de la política cultural para generar una alternativa sostenible y participativa al proyecto de la ciudad creativa basada en la orientación emprendedora, los grandes proyectos urbanísticos y los grandes eventos, que conforman el "modelo Barcelona".

\section{Conclusiones}

La gobernanza de la ciudad creativa y la corrección de los excesos economicistas e instrumentalistas son sin duda uno de los retos existentes de la política cultural. Algunos autores defienden que la perspectiva de la sostenibilidad debe marcar una nueva prioridad en la que se contribuya a un nuevo modelo de desarrollo y a un empoderamiento de la ciudadanía y la comunidad artística. El ideal en este contexto es poder combinar ciudad creativa con ciudad sostenible. El modelo de Barcelona de políticas culturales se ha convertido en un referente en España y a nivel internacional por su capacidad de articular el desarrollo urbanístico y la potenciación cultural de la ciudad. Su estrategia emprendedora se ha presentado como un equilibrio entre objetivos instrumentales, capacidad de generación de valor cultural y sensibilidad hacia la participación ciudadana. $Y$ en términos generales se presenta este modelo como un caso de éxito que se inició con la Olimpiada Cultural paralela a los Juegos Olímpicos de 1992. 
No obstante, la fallida experiencia del Fórum de las Culturas 2004 demostró que el equilibrio entre ciudad creativa y ciudad sostenible no siempre es posible. El Fórum, junto con los otros elementos, nos muestra que este equilibrio existe más en el plano discursivo que en la implementación efectiva de las recomendaciones a nivel internacional sobre las aportaciones de la cultura a un desarrollo sostenible. En general, hemos visto que a pesar de la retórica a favor de la sostenibilidad desarrollada en la Agenda 21 de la Cultura, la política cultural ha sido en general muy poco dirigida a fomentar la participación social y ha tenido poca capacidad para integrar aquellos sectores críticos con el "modelo Barcelona" de urbanismo o de política cultural.

¿Por qué esta discordancia entre discurso y realizaciones? Como hemos visto, la orientación emprendedora de la política cultural barcelonesa, enfocada al desarrollo de una ciudad creativa, posee unos condicionantes externos y una focalización, que impiden el desarrollo de políticas culturales más sostenibles y participativas. En primer lugar, la orientación emprendedora conlleva una falta, por definición, de planificación a medio y largo plazo. En segundo lugar, la participación de actores privados y de otras administraciones públicas condiciona la implementación de los proyectos y los hace menos vinculados a las necesidades de la comunidad local. Pero la falta de una orientación coherente con los discursos a favor de la sostenibilidad y de la participación no se debe solamente a factores exógenos. La política cultural ha priorizado la potenciación de los sectores culturales, lo que ha conllevado el dominio creciente de los lobbies de las industrias culturales. Este sesgo ha dificultado la atención a los retos de la inclusión social y la integración cultural y se ha expresado en la ausencia de interés por los centros de cultura comunitaria, los centros cívicos. Por otra parte, los mecanismos de gobernanza y participación en los Planes estratégicos o el Consejo de la Cultura han sido limitados a las industrias culturales y a los sectores más profesionalizados, dejando de lado las comunidades de artistas locales emergentes o la creación comunitaria. En ello ha jugado también el temor de los responsables de la política cultural a ver desbordados los marcos de participación con visiones críticas al desarrollo de proyectos urbanísticos y culturales.

En definitiva, podemos decir que a pesar del discurso a favor de la sostenibilidad y la participación, Barcelona parece haber apostado de facto por una política cultural orientada al fomento de las industrias culturales y el turismo, lo que a medio y largo plazo podría significar una pérdida de capacidad de generar valor cultural local al mismo tiempo que sería una ocasión perdida para la capacidad de la política cultural de vehicular nuevas 
formas de participación social. El caso de Barcelona muestra la dificultad de articular en un modelo de política cultural la estrategia emprendedora y generadora de valor cultural y económico, la ciudad creativa con la atención a las necesidades locales y a la participación, la ciudad sostenible. Una dificultad que demanda, por lo tanto, una revisión de los fundamentos y la aplicación del "modelo Barcelona" y una elección en el futuro entre el modelo de política cultural orientado hacia el desarrollo de la ciudad creativa o de la ciudad sostenible.

\section{Referencias bibliográficas}

Ajuntament de Barcelona (1980-2012), Pressupostos de l'Ajuntament de Barcelona. Gaseta Municipal. Barcelona: Ajuntament de Barcelona.

Ajuntament de Barcelona (2000), Pla d'Acció Municipal. Área de Cultura (2000-2003). Barcelona: Ajuntament de Barcelona.

Barber, Austin; Eastaway, Montserrat Pareja (2010), "Leadership Challenges in the Inner City: Planning for Sustainable Regeneration in Birmingham and Barcelona", Policy Studies, 31(4), 393-411.

Belfiore, Eleonora (2004), "Auditing Culture. The Subsidised Cultural Sector in the New Public Management", International Journal of Cultural Policy, 10(2), 183-202.

Bianchini, Franco (1993), Urban Cultural Policy in Britain and Europe: Towards Cultural Planning. London: Institute for Cultural Policy Studies.

Brenner, Neil (2004), "Urban Governance and the Production of New State Spaces in Western Europe 1960-2000”, Review or International Political Economy, 11(3), 447-488.

Brugué, Quim; Gomà, Ricard (1998), Gobiernos locales y políticas públicas. Barcelona: Ariel.

Cherbo, Joni M.; Wyszomirski, Margaret J. (2000), The Public Life of the Arts in America. Brunswick: Rutgers.

Consell de la Cultura de Barcelona (2011), Configuració del sistema públic de centres d'art i cultura contemporànies de Barcelona. Barcelona: Ajuntament de Barcelona.

Degen, Mónica; García, Marisol (2012), "The Transformation of the Barcelona Model?: An Analysis of Culture, Urban Regeneration and Governance”, International Journal of Urban and Regional Research, 36(5), 1022-1038.

Duxbury, Nancy; Jeannotte, M. S. (2010), "From the Bottom-up: Culture in Community Sustainability Planning", 3rd ESA Sociology of Culture research mid-term Conference, $1-15$.

Duxbury, Nancy; Jeannotte, M. S. (2011), "Introduction: Culture and Sustainable Communities", Culture and Local Governance, 3(1-2), 1-10.

Espai en Blanc (2004), La otra cara del Fórum de les Cultures S.A. Bellaterra: Edicions Bellaterra. 
Eurocities (2010), Eurocities Response to the Green Paper "Unlocking the Potential of Cultural and Creative Industries". Toward a European Integrated Strategy for Cultural and Creative Industries. Brussels: Eurocities.

Evans, Graeme (2001), Cultural Planning: An Urban Renaissance? London: Routledge.

Florida, Richard L. (2002), The Rise of the Creative Class: And How it's Transforming Work, Leisure, Community and Everyday Life. New York: Basic Books.

Font, Joan (2001), Ciudadanos y decisiones públicas. Barcelona: Ariel.

Font, Jordi (1991), Papers de politica cultural. Barcelona: Edicions 62.

García, Beatriz (2004a), "Urban Regeneration, Arts Programming and Major Events: Glasgow 1990, Sydney 2000 and Barcelona 2004”, International Journal of Cultural Policy, 10(1), 103-118.

García, Beatriz (2004b), "Cultural Policy and Urban Regeneration in Western European Cities: Lessons from Experience, Prospects for the Future”, Local Economy, 19(4), 312-326.

Gómez, Marí V.; González, Sara (2001), “A Reply to Beatriz Plaza’s 'The Guggenheim-Bilbao Museum Effect'”, International Journal of Urban and Regional Research, 25(4), 898-900.

Guillemat, Elisabet (2008), "El Plan Estratégico de cultura de Barcelona 2007-2015: nuevos acentos 2006”, in F. Manito (coord.), Planificación estratégica de la cultura en España. Madrid: Fundación Autor, 189-218.

Harvey, David (1989), "From Managerialism to Entrepreneurialism: The Transformation in Urban Governance in Late Capitalism." Geografiska Annaler. Series B, Human Geography, 71, 3-17.

Hawkes, Jon (2001), The Fourth Pillar of Sustainability. Culture's Essential Role in Public Planning. Victoria: Common Ground Publishing.

ICUB (1995), Memòria de Constitució de l'Institut de Cultura de Barcelona. Barcelona: Ajuntament de Barcelona.

ICUB (1999), Bcn, Accent de Cultura. Pla Estratègic del Sector Cultural de la Ciutat. Barcelona: Ajuntament de Barcelona.

ICUB (2006), Nous accents 2006. Pla Estrategic del Sector Cultural de Barcelona. Barcelona: Ajuntament de Barcelona.

Jeannotte, M. S.; Duxbury, Nancy (2010), "Culture, Sustainability and Communities: Exploring the Miths", Oficina do CES, 353.

Jessop, Bob (2004), "Multi-level Governance and Multi-level Metagovernance", in I. Bache; M. Flinders (coords.), Multi-level Governance. Oxford: Oxford University Press, 49-74.

Julier, Guy (1996), "Barcelona Design, Catalonia's Political Economy, and the New Spain, 1980-1986”, Journal of Design History, 9(2), 117-127.

Kagan, Sacha; Hahn, Julia (2011), "Creative Cities and (Un)Sustainability: From Creative Class to Sustainable Creative Cities”, Culture and Local Governance, 3(1-2), 11-27. 
Lash, Scott; Urry, John (1998), Economías de signos y espacio: Sobre el capitalismo de la posorganización. Buenos Aires: Amorrortu.

Majoor, Stan (2011), "Framing Large-Scale Projects: Barcelona Forum and the Challenge of Balancing Local and Global Needs", Journal of Planning Education and Research, 31(2), 143-156.

Marshall, Tim (1996), "Barcelona Fast Forward? City Entrepreneurialism in the 1980s and 1990s", European Planning Studies, 4(2), 147-165.

Marshall, Tim (2000), "Urban Planning and Governance: Is there a Barcelona Model?”, International Planning Studies, 5(3), 299-319.

Menger, Piere-Michel (2010), Cultural Policies in Europe. From a State to a City-centered Perspective on Cultural Generativity. Tokyo: National Graduate Institute for Policy Studies.

Muntaner, Josep M. (2007), “El modelo Barcelona”, El Pais, 12.06.2007, 56.

Pascual, Jordi (2008), "Cultural Policies, Human Development and Development Innovation: or Why We Need an Agenda 21 for Culture”, UNESCO Observatory Multi-disciplinary research in the Arts E-Journal, 1(2), 9-25.

Rius, Joaquim (2005), Un nou paradigma de la política cultural. Estudi sociològic del cas Barcelona. Barcelona: Universitat Autònoma de Barcelona-École des Hautes Études en Sciences Sociales.

Rodriguez Morató, Arturo (2005), "La reinvención de la política cultural a escala local: el caso de Barcelona”, Sociedade e Estado, 20(2), 351-376.

Rodriguez Morató, Arturo (2008), "La emergencia de una capital cultural europea", in M. Degen; S. García (orgs.), La metaciudad: Barcelona. Transformación de una metropolis. Barcelona: Antrophos.

Sánchez, Ma V. (2010), La Participación Cultural en los Centros Cívicos de la ciudad de Barcelona: Divergencias y convergencias entre modelos de gestión indirecta. Tese de Máster en Gestión Cultural. Barcelona: Universidad de Barcelona.

Scott, Allen (1999), "The Cultural Economy: Geography and the Creative Field", Media, Culture \& Society, 21(6), 807-817.

Sewell, William H. (1992), "A Theory of Transformation: Duality, Agency and Transformation”, American Journal of Sociology, 98(1), 1-29.

Subirós, Josep (1998), El vol de la fletxa. Barcelona'92: Crònica de la reinvenció de la ciutat. Barcelona: Electa.

Subirós, Josep (1999), Estrategias culturales y renovación urbana. Barcelona: Aula Barcelona.

Trullén, J. (2001), “El projecte Barcelona. Ciutat del coneixement des de l'economia”, Barcelona Metrópolis Mediterrániarcelona, 1, 16-25.

UCLG (2006), Advice on Local Implementation of the Agenda 21 for Culture. United Cities and Local Governments Working Group on Culture. Brussels: United Cities and Local Governments. 
50 | Ma. Victoria Sánchez Belando, Joaquim Rius Ulldemolins, Matías I. Zarlenga

Urfalino, Philippe (1996), L'invention de la politique culturelle. Paris: La Documentation Française.

Willis, Paul E. (1990), Common Culture: Symbolic Work at Play in the Everyday Cultures of the Young. London: Open University Press. 